DOI: $10.12957 /$ concinnitas.2019.47954

\title{
Visorama, por uma política do encontro ${ }^{1}$
}

\author{
Natália Quinderé ${ }^{2}$
}

Brígida Baltar, ao relembrar a importância da formação do Visorama, primeiramente, em torno do grupo de estudos, criado por Ricardo Basbaum, descreve um circuito de arte carioca, do final da década de 1980, desértico - precariedade na circulação de informações, inexistência de galerias e de feiras de arte, ausência de instituições fortes e de programas de pós-graduação nas universidades. Do esforço dispendido na elaboração de um dossiê Visorama e na coleta de lembranças de suas e seus participantes, é necessário exercitar nossa capacidade de forjar uma memória do futuro.

Que futuro?

Ao ler a descrição de Brígida, me pergunto:

O que mudou, fatalmente, no cenário artístico carioca?

Um museu pegou fogo em um domingo à noite - com sua destruição televisionada, prontamente. Outro teve obra de sua coleção permanente vendida sem consulta pública, com a justificativa de pagar os gastos do próprio museu. Um terceiro, recém-inaugurado (com menos de dez anos), viu seu orçamento minguar em decorrência de cortes das esferas privada-pública. Para onde o MAR vai escorrer?

Um departamento de arte em uma universidade, pasmem, também pegou fogo. Outro ficou cheio de lixo, com elevadores parados, técnicas, técnicos, professoras e professores sem receber salários. Bolsas da graduação e da pós foram cortadas. Para além dos museus e dos departamentos universitários, lugares de exposição temporárias também sofreram cortes ou foram encerrados. O Centro Municipal de Arte Hélio Oiticica, por exemplo, continua tendo programação ativa e diversa, sustentado por artistas e demais especialistas,

\footnotetext{
1 para os olhos da Analu

${ }^{2}$ Faz doutorado no Programa de Pós-graduação de Artes Visuais, da Escola de Belas, UFRJ. Estuda os museus de artista. Além da pesquisa acadêmica, é curadora.
} 
com suas propostas, projetos, aulas públicas. Apesar do esforço de sua equipe, a manutenção básica do centro sofre com a falta de dinheiro: da impossibilidade de trocar os filtros dos bebedouros ao corte da Internet.

"Com público de 48 mil pessoas, ArtRio supera pessimismo inicial com cenário econômico" - lia-se no título principal da matéria do jornal $O$ Globo, em 22 de setembro de 2019. As galerias comemoravam o sucesso de público e de vendas. A galerista Silvia Cintra afirma que vendeu, inesperadamente, obras de arte (sem especificar os trabalhos e os artistas) que valiam entre 50.000 a 250.000 reais. Márcio Botner, diretor e sócio da galeria A Gentil Carioca, comemora as vendas da instalação de Maxwell Alexandre a um colecionador dinamarquês; de uma tela de Arjan Martins para coleção portuguesa; de um trabalho de Maria Nepomuceno para o Panamá e; por último, de um trabalho de Vivian Cacuri, que seguirá, como a instalação de Maxwell, para a Dinamarca. Trabalhos que, dificilmente, voltarão ao Brasil. A venda de obras nacionais que não circularam em solo brasileiro abastece o mercado internacional, ao mesmo tempo que abre um buraco no mapeamento crítico nacional, como observa Ana Letícia Fialho em $O$ valor da obra de arte (2014).

Diria: tudo mudou, nada mudou.

É possível?

Se as informações e convites de aberturas, falas e eventos nos afogam na era da Internet e dos grupos de celular, se boas galerias continuam surgindo, inclusive, nos últimos anos, como, por exemplo, a Cavalo... propondo projetos individuais e exposições coletivas interessantes, o que nos diz a disparidade entre os "incêndios" nas instituições públicas/privadas - como o Museu de Arte Moderna do Rio (MAM-Rio), sempre na memória - que dependem de dinheiro público e da lei de incentivos fiscais para sobreviver, e a bonança (((inesperada))) das vendas das galerias, em 2019, na ArtRio? E, mais ainda, como essas relações contemporâneas tão díspares entre o público e o privado rememoram a agenda múltipla do Visorama do final da década de 1980 e início dos anos $90 ?$ 
Como Carla Guagliardi sugere, o Visorama se materializa em um momento histórico bastante singular. Quando a centelha do grupo surge, em 1988, o Brasil está em processo de redemocratização. O poder civil retoma seus direitos em 1985. Uma nova Constituição Federal é votada em 1988. As eleições diretas para a Presidência da República - primeira tentativa de Lula em ser eleito - ocorrem em 1989, um ano depois do surgimento do grupo de estudos. Seriam as primeiras eleições diretas em 29 anos. 29 anos! Atrelado à redemocratização do país, o neoliberalismo do Governo Collor aterrissou com força em nossas bandas, como nos contextualizou, Bernardo Mosqueira, em uma de suas perguntas aos integrantes do Visorama. No Rio e no restante do Brasil, naquele momento, algumas instituições culturais foram desmanteladas. Por exemplo, as galerias cariocas da Funarte - importantes espaços de exposição da cena contemporânea - são encerradas. O imaginário neoliberal, paradoxalmente, fabrica a importância da formação de um mercado brasileiro (livre do poder do Estado) e de sua relação, "regulatória", com o mercado estrangeiro.

O Visorama reverbera esse cenário histórico em suas práticas locais: no mapeamento e exame de trabalhos contemporâneos em escala global, por meio da reprodução de revistas, catálogos, livros internacionais, nomeadamente, do norte global (Artforum, Art in American, Flash Art, Arte Moderna, do Argan, Un-expressionism, do Germano Celant, o ensaio Escultura do Campo Ampliado de Rosalind Krauss, publicado em 1984, na revista Gávea etc.); no debate crítico sobre as mazelas do circuito de arte carioca, seguido de uma tentativa de cavar práticas em grupo e públicas que ultrapassem o deserto institucional. O entrelaçamento entre abertura democrática e formação de mercado, refletida no surgimento do Visorama, serve mais como metáfora de livre trânsito geográfico - de ideias, trabalhos, conceitos, artistas, curadores e da crescente importância das exposições temporárias como bienais e a Documenta - do que a formação de um comércio nacional e estrangeiro que sustente a produção artística carioca. Longe disso!

Interessa perceber como esses artistas, no final da década de 1980, se conectaram do Rio com uma cena internacional, mediante a proposição de ações múltiplas, para além dos encontros do grupo. Analu Cunha afirma que o Visorama foi um movimento estratégico na união. Estratégia de sobrevivência - completaria. O desejo do grupo de traçar um panorama das práticas contemporâneas fez emergir um arquivo. Nele, cada integrante estabelecia relações com sua própria pesquisa artística, mediante uma visão global. $\mathrm{O}$ 
mapeamento da cena global abarcava, também, a circulação de artistas brasileiros no exterior. A organização do evento, Visorama na Documenta (1992), no Parque Lage, contou com a participação de Jac Lerneir, Cildo Meireles, José Resende e Waltercio Caldas, para debaterem suas participações na Documenta 9. Foi o primeiro grupo de artistas brasileiros a participar da exposição, em Kassel, a convite do curador da mostra, Jan Hoet. O duplo movimento de olhar para o exterior e para a cena local parece ter fornecido, aos integrantes do Visorama, ferramentas para o desenvolvimento das pesquisas individuais de cada um, ao mesmo tempo que estas começam sendo legitimadas pelo próprio grupo.

Nas pesquisas individuais, compartilhadas em grupo, reverberam pontos de virada da cena contemporânea que, naquele momento, não parecem estar contemplados em nenhum lugar na cidade do Rio. Ivair Reinaldim destaca uma possível transformação dessas práticas no grupo, quando pergunta sobre uma "virada conceitual" no uso das imagens, na década de 1980. Cada integrante responde de maneira bastante distinta à pergunta de Ivair. A construção do arquivo, para Basbaum, seria um "gesto de intervenção e produção de valor”. João Modé se refere a um uso documental das imagens, sem entendimento conceitual. Carla Guagliardi prefere restituir o cenário social, político e cultural como recorte para o surgimento e para o trabalho do grupo. Finalmente, Analu Cunha reforça, sim, a ideia do uso de outra ordem das imagens, embora afirme que o Visorama não se encaixa na análise crítica generalista da década de 80 . Noutro momento, Rosângela Rennó explica como os encontros do grupo serviram como formação complementar ao estudo acadêmico da fotografia - já que a Eca, na Usp, onde a artista estudou, teria como foco a fotografia do século 19.

Em 2019, a bonança do mercado na feira de arte nos expõe ao forte emparelhamento da iniciativa privada em projetos e em práticas artísticas. Bancos, escritórios de advocacia, empresas de bebida, telefonia e etc. financiam o desenvolvimento de projetos artísticos e de exposições de arte. Atrelado a esse emparelhamento, é notável a recorrência de artistas de galerias influentes em exposições importantes em museus e em demais instituições. Esse cenário não seria preocupante se as pesquisas de muitas e de muitos artistas não fossem solapadas e inviabilizadas por esse tipo de financiamento, e se trabalhos de curadoria e pesquisas historiográficas também não ficassem à mercê dos desejos publicitários de quem os financia - lembro das ambiguidades da morte da obra no museu, 
em Adorno, e da noção de consumo em Elogio da Profanação, em Agamben. Nada novo no universo da arte, mas, de uma só vez, tudo novo de novo. Quais os limites dos financiamentos privados (e públicos) no desenvolvimento das práticas e pesquisas artísticas que, segundo Pedrosa - reproduzido, aqui, na voz de Valeska Soares -, deveriam ser um exercício experimental da liberdade?

Brígida afirma amorosamente que um dos ensinamentos do Visorama foi o de lhe ter proporcionado a coragem para se lançar na vida. Arte como existência. Percebo nas respostas do grupo que esses encontros produziram uma descarga de energia. Energia que reverbera nos integrantes até hoje. Ao ler a entrevista de cabo a rabo, penso que um dos ensinamentos do Visorama ao qual somos expostos é o da força irruptiva dos encontros.

A força irruptiva dos encontros.

A energia gerada pelo estar junto que promove, ali, no encontro mesmo, novos tipos de institucionalidades. Novas formas de se relacionar com o que é privado e com o que é público. O que dever ser partilhado? O que deve ser tornado visível? Apesar da falta de políticas públicas de curto, médio e longo prazo que financiem o trabalho de artistas e demais pesquisadores dentro e fora das universidades, a cidade do Rio de Janeiro está repleta de lugares onde se cavam encontros. Lugares mantidos pela cena artística: A Mesa, Centro Cultural Phábrika, a finada Caixa Preta, Aparelho, Fosso, galeria Desvio, Lanchonete $<>$ Lanchonete, Capacete, para citar apenas alguns. Esses espaços têm agregado pessoas de várias práticas artísticas, faixas etárias, e proposto debates pertinentes para as artes visuais e para além dela.

Se o Visorama tem sua importância historiográfica medida pelo esforço de mapear suas ações no intuito de traçar suas singularidades, a partir um recorte histórico, é na sua relação com a cena contemporânea carioca que a formação do grupo, no final da década de 1980, ecoa em nós seu traço: nos expõe o encontro como um fazer político da arte.

Nada mudou. Tudo mudou.

25 de outubro de 2019 